\title{
Peynirde Biyojen Amin Varlığı ve Tespit Edilme Yöntemleri
}

\author{
Büşra GÖNCÜ ${ }^{1}$, Musa Serdar AKIN ${ }^{1}$, Mutlu Buket AKIN ${ }^{1}$ \\ ${ }^{1}$ Harran Üniversitesi, Ziraat Fakültesi, Gıda Mühendisliği Bölümü, Şanlıurfa \\ *Sorumlu yazar: busragoncu@harran.edu.tr
}

\begin{abstract}
Öz
Biyojen aminler (BA); mikrobiyal, hayvansal ve bitkisel metabolizmalar tarafından sentezlenen toksik bileşiklerdir. Genel olarak aminoasitlerin dekarboksilasyonu yoluyla veya aldehit ve ketonların aminasyon ve transaminasyonu ile oluşmaktadır. Balık, şarap, peynir gibi proteince zengin ve fermente edilmiş gıda maddelerinin üretimi, işlenmesi ve depolanması sırasında oluşan, hem gıdaların bozulmasından hem de gıda zehirlenmesine neden olmaktadır. Özellikle peynir; uygun kofaktör varlığı yanı sıra onların büyümelerine izin veren çevre koşulları ve dekarboksilaz (+) mikroorganizmaların olası varlığı, proteoliz seviyesinin bir sonucu olarak serbest aminoasitlerin üretimini kapsayan amin üretimi için ideal bir substrattır. BA'nın oluşumu gıda bozulmasının bir göstergesi olduğu için bu bileşiklerin tespiti önemlidir. BA'nın tespitinde uygulanan kromatografik yöntemler en uygun yöntemlerdir. Bunlar içinde en çok kullanılanı HPLC (yüksek performans sıVı kromatografisi)'dir. Ayrıca BA; dekarboksilaz pozitif mikroorganizmaların uygun koşullar altında gerçekleştirdikleri enzim aktivitesi ile de üretilebilmektedir. Bu yüzden gıda içeriğindeki BA'nın riskinin tahmin edilmesi açısından dekarboksilaz aktiviteli bakterilerin tespiti önemlidir. Bu yüzden BA tespitinde kullanılan moleküler teknikler de gittikçe önem kazanmaktadır. Bu çalışmada peynirde biyojen amin varlığı ve tespit edilme yöntemleri anlatılmıştır.
\end{abstract}

Anahtar Kelimeler: Biyojen amin, Peynir, Dekarboksilaz

\section{Existence of Biogenic Amines in Cheese and Detection Methods}

\begin{abstract}
Biogenic amines (BA) are toxic compounds which are synthesized by microbial, animal and herbal metabolisms. They are formed by several methods such as amino acid decarboxylation, aldehyde and ketone amination - transamination, deformation of fish, cheese, red meat which are rich in protein. Cheese, especially, is an ideal substrat for aminoacid production in existence of proper cofactor, decarboxylase (+) microorganisms and level of proteolysis. It is a crucial food quality control to detect such toxic compounds due to formation of BA is a sign of food decomposition. The best detection method is HPLC (high performance liquid chromatography). Biogenic amines are not only produced by decarboxylase activity but also released by enzymes of decarboxylase (+) microorganisms. Therefore, it is important to detect decarboxylase bacterias. For the same purpose, modern molecular techniques become popular and crucial. In this study, presence of biogenic amines in cheese and detection methods are explained.
\end{abstract}

Key Words: Biogenic amines, Cheese, Decarboxylase

\section{Giriş}

Gıdalardaki biyojen aminler gıdaların bozulması ve gıda güvenliği açısından önemli bileşenlerdir. Bu aminler, hammaddeye özgü
dekarboksilaz
aktivitesi
sonucunda üretilebildikleri gibi, dekarboksilaz pozitif mikroorganizmaların uygun koşullar altında gerçekleştirdikleri enzim aktivitesi ile de üretilebilmektedir (Karahan, 2003). Gıdaların 
mikrobiyal bozulması sırasında dekarboksilaz aktivitesi arttığından, biyojen aminlerin varlığı gıda bozulmasının göstergesi olması açısından büyük önem taşımaktadır (Karahan, 2003; Vatansever, 2004). Böylelikle gıdalardaki biyojen aminlerin belirlenmesi ile gıda kalitesi hakkında bilgi edinilmesi mümkün olmaktadır. Gıda kalitesi açısından önemli biyojen aminler, diaminlerden putresin ve kadaverin, poliaminlerden spermin ve spermidin, aromatik aminlerden tiramin ve heterosiklik aminlerden triptamin, histamin ve 2 -feniletilamindir (Karahan, 2003).

Çizelge 1. Biyojen Aminlerin Sınıflandırılması Table 1. Classification of Biogenic Amines

\begin{tabular}{|c|c|c|}
\hline \multicolumn{3}{|c|}{$\begin{array}{c}\text { Kimyasal Yapılarına Göre } \\
\text { According to Chemical Structures }\end{array}$} \\
\hline Aromatik Aminler & Alifatik di-, tri- ve Poliaminler & Alifatik Uçucu Aminler \\
\hline Aromatic Amines & Aliphatic di-, tri- and Polyamines & Volatile Aliphatic Amines \\
\hline Histamin & Putresin & Metilamin \\
\hline Tiramin & Kadaverin & Etilamin \\
\hline$\beta$-feniletilamin & Agmatin & İzopentilamin \\
\hline Triptamin & Spermin & Etanolamin \\
\hline Serotonin & Spermidin & \\
\hline \multicolumn{3}{|c|}{ Azot Sayısına Göre } \\
\hline \multicolumn{3}{|c|}{ Number of Nitrogen } \\
\hline Monoaminler & Diaminler & Poliaminler \\
\hline Monoamines & Diamines & Polyamines \\
\hline Metilamin & Histamin & Agmatin \\
\hline Etilamin & Triptamin & Spermin \\
\hline İzopentilamin & Putresin & Spermidin \\
\hline Etanolamin & Kadaverin & \\
\hline$\beta$-feniletilamin & Serotonin & \\
\hline Tiramin & & \\
\hline
\end{tabular}

Peynirde biyojen amin oluşumu çok sayıda faktöre bağlıdır. Ortamda serbest aminoasitlerin varlığı ve üretim sırasında eklenen mikroorganizmalar veya kontamine olan mikroorganizmalar biyojen amin oluşumuna neden olmaktadır. Ayrıca üretimin hijyenik olmayan koşullarda gerçekleştirilmesi mikrobiyal bozulmayı
Peynir, BA kontaminasyonuyla ilişkili fermente gıdalardan en yaygın olanıdır. Özellikle olgunlaşma sırasında proteolotik enzimler kazeinin parçalanmasına ve ortamda bulunan serbest aminoasitlerin artmasına yol açar. Bu aminoasitlerin bakteriyel enzimlerle dekarboksilasyonu sonucunda ise biyojen aminler oluşur. Peynirlerde bulunan başlıca biyojen aminler; histamin, tiramin, triptamin, putresin, kadaverin, $\beta$-feniletilamindir (Durlu Özkaya ve ark., 1999). arttırmaktadır. Mikrobiyal gelişim ve dekarboksilaz aktivitesi için gerekli koşulların $(\mathrm{pH}$, tuz konsantrasyonu, sıcaklık, su aktivitesi, olgunlaştırma sıcaklığı ve zamanı, depolama sıcaklığı, uygun kofaktörlerin ortamda bulunması) olması da diğer önemli faktörlerdir. Bu nedenle peynirde bulunan biyojen amin miktarları da değişmektedir. 
Peynirin $\mathrm{pH}^{\prime} \mathrm{s}$ 1 5.0-6.5 arasında olup, bu değerler dekarboksilaz aktivitesi için idealdir. Histamin ve diğer biyojen aminlerin oluşumu yüksek sıcaklıkta artmaktadır. Olgunlaştırma işleminin süresi arttıkça, biyojen amin miktarının da arttığını göstermektedir. Peynirlerde gerçekleştirilen çalışmalara baktığımızda farklı biyojen aminlerin çok farklı düzeylerde bulunduğu tespit edilmiştir. Taze peynir, süt ve yoğurttaki en yaygın aminler spermidin ve spermindir. (Gezginc ve ark., 2013). Peynirlerde ise toplam amin eşik değer riski $100 \mathrm{mg} \mathrm{kg}^{-1}$ olarak bulunmuştur (Schirone ve ark., 2011).

Türk Gıda Kodeksi'nde süt ve ürünleri için belirlenmiş herhangi bir limit bulunmamakla beraber, su ve su ürünleri için $100-200$ mg kg${ }^{1}$ olarak belirtilmiştir (TGK, 2011). Süt, yoğurt, lor peyniri ve taze peynirde yapılan çalışmalarda BA miktarı kg başına 10 mg'ye kadar diğer fermente ürünlerde ise BA miktarının $15 \mathrm{mg} \mathrm{kg}^{-1}$ seviyesini aşmaması gerektiği bildirilmiştir. (Buňková ve ark., 2013). BA'nın oluşumu gıda bozulmasının bir göstergesi olduğu için miktarının belirlenmesi önemli bir gıda kontrol metotudur (Erim, 2013). BA miktarının belirlenmesinde yaygın olarak kullanılan metotlar iki gruba ayrılır:

\section{BA Belirlenmesine Dayanan Yöntem}

Ince tabaka kromatografisi (TLC), gaz-sıvı kromatografisi (GLC) ve yüksek performans SIVI kromatografisi (HPLC) biyojen amin analizlerinde yoğun bir şekilde kullanılan kromatografik yöntemlerdir (Shakila ve ark., 2001). Bunlar içinde HPLC en çok kullanılan yöntem olup, flourometrik ve enzimatik yöntemlerin yanı sıra elektroforez de kullanılmaktadır (Yerlikaya ve Gökoğlu, 2002). Özellikle son yıllarda yapılan çalışmalara bakıldığında kapiler elektroforez yönteminin kullanıldığı çalışmalara da sıklıkla rastlanılmaktadır. Kapiler elektroforez yöntemi diğer yöntemlere alternatif teşkil etmektedir. Bazı durumlarda türevlendirmeye gereksinim duyulmaması, örnek saflaştırmanın gerekmemesi, kısa analiz zamanı bu metotun en önemli avantajlarıdır. Salam, peynir, şarap, bira örneklerinde biyojen aminlerin belirlenmesi için yapılan bir çalışmada türevlendirme yapılmamış, herhangi bir saflaştırma basamağı uygulanmamış $15 \mathrm{dk}$ 'dan daha kısa bir sürede kapiler elektroforez-iletkenlik dedektörü tespit yöntemiyle analizler gerçekleştirilmiştir (Kvasnicka ve Voldrich, 2006). Bira örneklerinde gerçekleştirilen çalışmada ise 10 farklı biyojen amin kapiler elektroforezlazerle indüklenmiş floresans dedektör kullanılarak belirlenmiştir ve analizler 30 dk'dan kısa sürede gerçekleştirilmiştir. (Cortacero-Ramirez ve ark., 2007). Kapiler elektroforez yöntemleri duyarlılık, doğrusallık, tespit limiti, tekrarlanabilirlik, doğruluk ve kesinlik açısından da oldukça iyi sonuçlar vermektedir. Bu konuda yapılan çalışmalar literatürde incelendiğinde farklı gıda gruplarında biyojen aminlerin belirlenmesinde kapiler elektroforez yöntemlerinin kullanılabileceği görülmektedir (Önal, 2007). HPLC yöntemi ise gıdalarda biyojen amin analizinde en fazla kullanılan yöntemlerden biridir. Bu yöntemle biyojen aminlerin belirlenebilmesi için genel olarak C18 kolon kullanılmakta, dereceli elüsyon tekniği kullanılarak absorbans dedektör veya floresans dedektörde analizler gerçekleştirilmektedir (Özdestan ve Üren, 2006). Ultra Yüksek Basınçlı SıVı Kromatografi (UHPLC) metotu ise HPLC'nin prensibi ve uygulamasını gerektiren, hızlı ve güvenilir yeni bir jenerasyon kromatografik tekniğidir. Bu metotta hız, duyarlılık ve ayrışma daha iyidir. Geleneksel HPLC metotları çok çeşitli BA'ların belirlenmesine izin vermesine rağmen analizin uygulanması 
için gereken zaman, UHPLC'ye göre her örnek için yaklaşık 20-60 dk daha uzundur. Belli peynir tiplerinde HPLC metotu kullanımı BA'nın belirlenmesi için bazı durumlarda uygun olmamakta ve çok zaman tüketmektedir. Ancak UHPLC metotu daha kısa işlem süresi, daha yüksek çözünürlük ve duyarlılık nedeniyle geleneksel HPLC sisteminden üstün olduğu kanıtlanmıştır (Mayer ve ark., 2010). BA'lar aminoasitlerden elde edildiği için bileşenlerin her iki sınıfının eşzamanlı belirlenmesi için hassas metotlar önerilmektedir. Mazzucco ve ark. (2010), peynirde BA örneklerinin eşzamanlı belirlenmesi için ters-faz HPLC metotunu geliştirmişlerdir. Araştırıcılar 4 amini (kadaverin, histamin, tiramin, triptamin) ve bu aminlerin öncül 4 aminoasitlerini (lisin, histidin, tirozin, triptofan) belirlemişlerdir.

Yine başka bir çalışmada UHPLC ile DEEMM (dietiletoksimetilenemalonat) reaktifi kombinasyonunun peynir örneklerinde BA, amonyum iyonu ve aminoasit içeriğini eşzamanlı olarak belirlemek için güvenli bir metot olarak kullanılabileceği tespit edilmiştir. Bu teknikle diğer tekniklerde gerekenden daha az hacimde çözücü kullanarak çok fazla sayıda örneğin analizini ve peynir amino bileşiği kompozisyonun doğru belirlenmesini sağlamakta ve olgunlaştırma sırasında proteolizin izlenmesinde kullanılabilmektedir (Bunkova ve ark., 2013). Jia ve ark., (2011) farklı peynirlerde BA'lar ve çok çeşitli aminoasitlerin eşzamanlı belirlenmesine izin veren kuadrupol kütle spektrometrisi (Q-TOF) ile LC metotu çiftinin daha etkili olduğunu kanıtlamışlardır. Son zamanlarda peynirde BA belirlenmesi için yeni bir sIVI kromatografisi (LC) metotu olan ELSD (evaporatif ışık saçan dedektör) kullanılmıştır. ELSD'nin esası; ışık hüzmesinden geçen bir çözücünün evaporasyonu yoluyla saçılan ışık miktarına dayanır. Sonuçta elde edilen sinyal, çözücünün evaporasyonu sırasında evapore olmayan veya kompozisyonu bozulmayan örnekte mevcut olan bütün bileşenler için uygun olmaktadır (Loizzo ve ark., 2013). Bu bakımdan LC metotları kütle spektrometri ile birleştirilmiştir. Ayrıca ELSD kütle spektrometriden daha ekonomik ve geniş yelpazede çözücüyle uyumlu olmuştur (Sipizzirri ve ark., 2013).

\section{2. Üretici Mikroorganizmanın Belirlenmesine Dayanan Yöntem}

Mikroorganizmaların dekarboksilaz aktivitesi son derece değişkendir, pek çok durumda suşa bağlıdır. Bu yüzden bu bakterilerin tespiti sadece gıda içeriğindeki BA'nın riskini tahmin edilmesi açısından değil aynı zamanda fermente gıdalarda birikmesinin önlenmesi bakımından da önemlidir. BA üreten suşların tanımlanması için PCR'ye dayalı yeni metotlar geliştirilmiştir. Özellikle peynir örneklerinde başarıyla kullanıımıştır. Bu tekniğin önemli bir yararı BA'lar belirlenmeden önce üretici mikroorganizma belirlenmekte ve muhtemelen son üründe $\mathrm{BA}$ birikimi tahmin edilebilmektedir. Bu metot peynir üretiminin her aşamasında kullanılabilmektedir (Loizzo ve ark., 2013).

Kantitatif gerçek zamanlı PCR; genlerin miktarı, gen ekspresyonu ve üreticilerin hızlı belirlenmesi açısından oldukça kullanışlı olmaktadır. Farklı qPCR denemelerinde, farklı gıda matrislerindeki BA üretebilen gram (+) bakteri miktarı ve belirlenmesi geliştirilmiştir. Son zamanlarda bu metot balıkta histamin üreten gram (-) bakteri belirlenmesinde uygulanmıştır. Böylelikle HPLC tarafından belirlenemeyen BA üreticilerin varlığını belirlemekte ve geleneksel peynirlerde güvenliği ve kaliteyi geliştirmek açısından uygulanabilmektedir (Schirone ve ark., 2013). 
Marcobal ve ark. (2004), gıdalardaki histamin, tiramin ve ornitin üreten laktik asit bakterilerinin eş zamanlı tespitlerinde multiplex polimeraz zincir reaksiyonu metotunu kullanmışlardır. Fermente gidalarda histamin, tiramin ve ornitin üreten LAB suşlarının eş zamanlı tespitinde kullanılan çoklu polimeraz zincir reaksiyonu analizleri hakkında üç çift primer tasarlamışlardır. Hedef mikroorganizmaların DNA'ları aynı tepkimeye konulduğunda farklı iki ya da daha fazla boyuta karşılık gelen çoğalmalar tespit edilmiştir. Bu analizin kontrollü koleksiyon cinslerindeki amin üreten bakterilerin tespitinde ve $L A B$ koleksiyonunda faydalı olduğu ve LAB'nin bu biyojen aminleri üretmeyen cinslerin DNA'sında hiçbir ayrıntı gözlenmediği bildirilmiştir. Bu çalışmada öncül LAB'ın doğru seçilmesinde yapılan rutin taramalarda ve gıda içi kontrol laboratuvarlarına kolaylıkla dahil edilebileceği bildirilmiştir.

Landete ve ark. (2007), şaraplardan izole edilen çeşitli asetik asit bakterileri, maya bakterileri ve laktik asit bakterilerinde biyojen amin tespiti yapmışlardır. LAB grubu içerisinde bulunan 155 adet Lactobacillus ssp., $O$. oeni ve Pediococcus ssp. türlerinde tiramin (tdc), histamin (hdc) ve pütresin (odc) genlerini tespit etmişlerdir. Hollanda tipi yarı sert peynirde olgunlaşma süresince $B A$ üretimi için starter kültür kaynaklı tür olarak 13 adet Enterococcus ve 3 adet Lactobacillus cins türleri izole edilmiştir. PCR yöntemi ile tiramin (trydc) ve histamin (hdc) dekarboksilaz enzimlerini kodlayan spesifik DNA dizilerinin varlığı tespit edilmiş ve bu HPLC yöntemiyle doğrulanmıştır. Enterococcus' larda tiramin ve histamin dizi karşılaştırılmasında \%89 Lactobacillus' larda ise \%99 oranında benzerlik tespit edilmiştir. Enterococcus cinsinden $E$. durans türünden 7 adet, E. faecalis türünden 3 adet, E. faecium türünden 1 adet, E. casseliflavus türünden 3 adet, $L$. curvatus, $L$. lactis ve $L$. helveticus türlerinden $1^{\prime}$ er adet izole edilmiş ve bunlardan sadece $E$. durans türünde tiramin üretimi gözlenmemiştir (Burdychova ve Komprada, 2007).

Martuscelli ve ark. (2005), tarafından gerçekleştirilen çalışmada ise starter kültür kullanmadan, çiğ süt kullanılarak üretilen (A) ve starter kültür kullanarak, pastörize süt kullanılarak üretilen (B) Pecorino Abruzzese peynirlerinde üretim ve olgunlaştırma sırasında oluşan biyojen amin miktarları karşılaştırılmıştır. Pecorino Abruzzese peyniri yarı-sert bir İtalyan peyniridir ve farklı yöntemlerle üretilebilmektedir. Biyojen amin analizleri HPLC'de C18 kolon kullanılarak gerçekleştirilmiştir. Hareketli faz olarak asetonitril ve fosfat tamponu (pH:7) kullanılmıştır. Analizlerde dereceli elüsyon tekniğinden yararlanılmıştır. Örnekler $0.1 \mathrm{M}$ $\mathrm{HCl}$ ile ekstrakte edilmiş, soğutmalı santrifüj işlemi uygulanmış ve süzülmüştür. Elde edilen ekstrakt dansil klorür ile $40{ }^{\circ} \mathrm{C}^{\prime}$ de $60 \mathrm{dk}$ süreyle türevlendirilmiştir. 60 günlük olgunlaştırma işlemi sonucunda peynirlerin toplam biyojen amin içeriği A için $697 \mathrm{mg} \mathrm{kg}^{-1}$ B için $1086 \mathrm{mg} \mathrm{kg}^{-1}$ olarak bulunmuştur. Enterobacteriaceae familyasındaki mikroorganizmalar ve laktik asit bakterilerinin biyojen amin oluşturma üzerine etkin oldukları belirlenmiştir. A grubunda toplam biyojen amin miktarı ilk 14 günde $34 \mathrm{mg} \mathrm{kg-}$ ${ }^{1}$ dan $401 \mathrm{mg} \mathrm{kg}^{-1}$ 'a kadar artmıştır. 14 ile 60 gün arasında ise az bir artış göstermiştir. B grubunda ise diğer grubun tersine 30 ile 60 gün arasında \%77'lik bir artış gözlenmiştir. Bu peynirlerde etilamin, tiramin, putresin, histamin, kadaverin, triptamin, -feniletilamin, spermin ve spermidin tespit edilmiştir. A grubunda en fazla bulunan biyojen aminler histamin (\%38), tiramin (\%26) ve putresindir (\%9). B grubunda ise - feniletilamin (\%28), 
tiramin (\%23), etilamin (\%15) ve putresin (\%15) en fazla bulunan biyojen aminlerdir.

\section{Sonuçlar}

Insan ve hayvan vücudunda biyolojik olarak önemli olan biyojen aminler, fazla miktarda alındıklarında herhangi bir nedenden dolayı yüksek konsantrasyonlarda oluştuklarında veya organizmadaki indirgenmeleri engellendiğinde toksik etkileri sebebiyle sağlığı tehlikeye sokabilmektedirler. Biyojen aminler mikrobiyal fermentasyonun ve bozulmanın gerçekleştiğini göstermektedir. Bu nedenle gıda güvenliğini kontrol altına almadaki en önemli etkenlerden olan limit değerlerinin belirlenmesi çok büyük önem taşımaktadır. Amino asit dekarboksilasyonu türe, suşa ve çevre şartlarına göre farklılık göstermektedir. Dolayısı ile izole edilmiş türlerde biyojenik amin üretme özelliklerinin tespit edilmesi önemlidir. BA' ların belirlenmesi sonucunda gıda kalitesi hakkında bilgi edinilmesi mümkün olmaktadır. Ayrıca erken ve hızlı olarak biyojen amin belirlenmesi, biyojen aminlerin oluşumunun önlenmesi bakımından önemlidir.

\section{Kaynaklar}

Buňková, L., Adamcová, G., Hudcová, K., Velichová, H., Pachlová, V., Lorencová, E., Buňka, F., 2013. Monitoring of biogenic amines in cheeses manufactured at smallscale farms and in fermented dairy products in the Czech Republic. Food Chemistry, 141 (1): 548-551.

Burdychova, R., Komprada, T., 2007. Biogenic amine-forming microbial communities in cheese. FEMS Microbiol. Lett, 276: 149155.

Cortacero-Ramírez, S., Arráez-Román, D. SeguraCarretero, A., Fernández-Gutiérrez, A., 2005. Determination of biogenic amines in beers and brewing-process samples by capillary electrophoresis coupled to laser- induced fluorescence detection. Food Chemistry, 100:383-389.

Durlu-Özkaya, F., Alichanidis, E., Tunail, N., 1999. Determination of biogenic amine content of beyaz cheese and biogenic amine production ability of some lactic acid bacteria. Milchwissenschaft, 54 (12): 680682.

Erim, F.B., 2013. Recent analytical approaches to the analysis of biogenic amines in food samples. Trends in Analytical Chemistry 52: 239-247.

Gezginc, Y., Akyol, İ., Kuley, E., Özogul, F., 2013. Biogenic amines formation in Streptococcus thermophilus isolated from home-made natural yogurt. Food Chemistry, 138 (1): 655-662.

Jia, S., Kang, Y.P., Park, J.H., Lee, J., Kwon, S.W., 2011. Simultaneous determination of 23 aminoacids and 7 biogenic amines in fermented food samples by liquid chromatography/quadrupole time-offlight mass spectrometry. Journal of Chromatography A, 1218 (51): 9174-9182.

Karahan, A.G., 2003. Gıdalarda biyojen aminler. Orlab On-Line Mikrobiyoloji Dergisi, 1 (5): 21-32.

Kvasnicka, F., Voldrich, M., 2006, Determination of biogenic amines by capillary zone electrophoresis with conductometric detection. Journal of Chromatography A, 1103:145-149.

Landete, J. M., Ferrer, S., Pardo, I., 2007. Biogenic amine production by lactic acid bacteria, acetic acid bacteria and yeast isolated from wine. Food Control, 18 (12):1569-1574.

Loizzo, M.R., Menichini, F., Picci, N., Puoci, F., Sipizzirri, U.G., Restuccia, D., 2013. Technological aspects and analytical determination of biogenic amines in cheese. Trends in Food Science \& Technology, 30 (1): 38-55.

Mayer, H.K., Fiechter, G., Fischer, E., 2010. A new ultra-pressure liquid chromatography method for the determination of biogenic amines in cheese. Journal of Chromatography A, 1217 (19): 3251-3257.

Marcobal, A., De Las Rivas, B., Moreno-Arribas, M.V., Munoz, R, 2004. Identification of the ornithine decarboxylase gene in the putrescine producer Oenococcus oeni BIFI83. FEMS Microbiol. Lett., 239: 213-220.

Martuscelli, M., Gardini, F., Torriani, S., Mastrocola, D., Serio, A., Chaves-Lopez, C., Schirone, M., Suzzi, G., 2005. Production of 
biogenic amines during the ripening of pecorino abruzzese cheese. International Dairy Journal, 15: 571-578.

Mazzucco, E., Gosetti, F., Bobba, M., Marengo, E., Robotti, E., Gennaro, M. C., 2010. Highperformance liquid chromatographyultraviolet detection method for the simultaneous determination of typical biogenic amines and precursor amino acids applications in food chemistry. Journal of Agricultural and Food Chemistry, 58 (1): 127-134.

Önal, A., 2007. Current analytical methods for the determination of biogenic amines in foods. Food Chemistry, 103: 1475-1486.

Özdestan, Ö., Üren, A., 2006. Biyojen amin analiz yöntemleri. Akademik Gıda, 4 (20): 19-24.

Schirone, M., Tofalo, R., Mazzone, G., Corsetti, A., Suzzi, G., 2011. Biogenic amine content and microbiological profile of pecorino di farindola cheese. Food Microbiology, 28 (1): 128-136.

Shakila, R.J., Vasundhara, T.S., Kumudavally, K.V., 2001. A comparision of the TLCdensitometry and HPLC method for the determination of biogenic amines in fish and fishery products. Food Chemistry, 75: 255-259.

Sipizzirri, U.G., Restuccia, D., Curcio, M., I. Parisi, O., Lemma, F., Picci, N., 2013. Determination of biogenic amines in different cheese samples by LC with evaporative light scattering detector. Journal of Food Composition and Analysis, 29 (1): 43-51.

Schirone, M., Tofalo, R., Fasoli, G., Perpetuini, G., Corsetti, A., Manetta, A.C., Ciarrocchi, A., Suzzi, G., 2013. High content of biogenic amines in pecorino cheeses. Food Microbiology, 34 (1): 137-144.

Türk Gıda Kodeksi, Mikrobiyolojik Kriterler Yönetmeliği, Resmi Gazete, 29 Aralık 2011. Sayı: 28157 (3. Mükerrer)

Vatansever, L., 2004. Et ve et ürünlerinde biyojenik amin ürünler. Kafkas Üniversitesi, Veterinerlik Fakültesi Dergisi, 10 (2): 203208.

Yerlikaya, P., Gökoğlu, N., 2002. Gıdalarda biyojen aminler ve önemi. Gıda Mühendisliği Dergisi, 6 (12): 24-30. 